

\section{Panta Rei \\ Revista Digital de Ciencia \\ y Didáctica de la Historia}

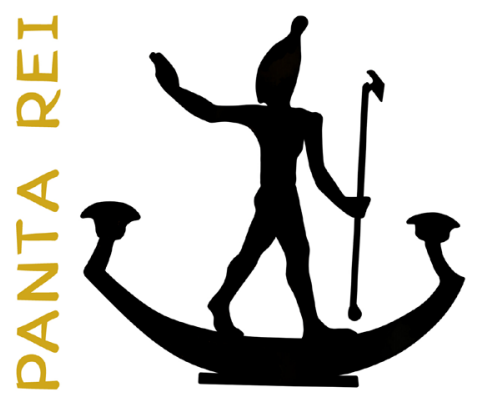

2017

Revista anual

Fecha de inicio: 1995

Revista Panta Rei. pantarei@um.es

Edita:

Centro de Estudios del Próximo Oriente y la

Antigüedad Tardía - CEPOAT

Edificio Universitario Saavedra Fajardo.

Universidad de Murcia

C/ Actor Isidoro Máiquez, 9

30007 - MURCIA - ESPAÑA

Teléfono: (+34) 868883890

cepoat@um.es

Web: www.um.es/cepoat/pantarei

Edición 2017

ISSNe: 2386-8864

ISSN: 1136-2464

Depósito legal: MU-966-1995
cepoAt

UNIVERSIDAD DE MURCIA centro de estudios del próximo oriente y la antigüedad tardia

En Portada: Kaaba durante el Ramadán. Fotografía de Abdullah Shakoor. Creative Commons CCO.

Responsables de los textos: Sus autores.

Responsable de la presente edición: Consejo Editorial Panta Rei. 


\section{CONSEJO DE REDACCIÓN}

\section{Coordinador editorial}

Egea Vivancos, Alejandro

[Didáctica de las Ciencias Sociales, UMU]

\section{Editores}

Botí Hernández, Juan Jesús

[CEPOAT, UMU]

Meseguer Gil, Antonio José

[UNED]

Sáez Giménez, David Omar

[CEPOAT, UMU]

Sánchez Mondéjar, Celso Miguel

[Patrimonio Inteligente]

\section{Secretaria}

Arias Ferrer, Laura

[Didáctica de las Ciencias Sociales, UMU]

\section{Responsable informático}

Martínez García, José Javier

[CEPOAT, UMU]

\section{Traducción y corrección lingüística}

Martínez Martínez, Cristina

[Sociedad Española de Lenguas Modernas]

Albaladejo Albaladejo, Sara

[ISEN, UMU]

\section{CONSEJO ASESOR}

Albero Muñoz, M. ${ }^{a}$ del Mar

[H. ${ }^{a}$ del Arte, UMU]

Chapman, Arthur

[History Education, UCL, Reino Unido]

Cobacho López, Ángel

[Derecho, UMU]

Egea Bruno, Pedro M. ${ }^{a}$

[Historia Contemporánea, UMU]

García Atienzar, Gabriel

[Prehistoria, UA]

González Monfort, Neus

[Didáctica de las Ciencias Sociales, UAB]

Haber Uriarte, María

[Prehistoria, UMU]

Hutson, Scott R.

[Anthropology, UK, EEUU]

Irigoyen López, Antonio

[Historia Moderna, UMU]

Mahony, Simon

[Digital Humanities, UCL, Reino Unido]

Marsilla de Pascual, Francisco Reyes

[Técnicas historiográficas, UMU]

Miralles Maldonado, José Carlos

[Filología Clásica, UMU]

Molina Gómez, José Antonio

[Historia Antigua, UMU]

Noguera Celdrán, José Miguel

[Arqueología, UMU]

Pérez Molina, Miguel Emilio

[Filología Clásica, UMU]

Prados Martínez, Fernando

[Arqueología, UA]

Sánchez Ibáñez, Raquel

[Didáctica de las Ciencias Sociales, UMU]

Sancho Gómez, Miguel Pablo

[Educación, UCAM]

Vilar García, María José

[Historia Contemporánea, UMU]

Zamora López, José Ángel

[Próximo Oriente Antiguo, CCHS-CSIC] 

Artículos

Entre el mito y la historia: el Éxodo de los israelitas desde Egipto a Canaán.

David Villar Vegas.

El Cerro de la Ermita de La Encarnación (Caravaca de la Cruz, Murcia): santuario y territorio en el mundo ibérico del Sureste peninsular.

Leticia López-Mondéjar.

Estelas discoideas y mundo funerario en la Asturias antigua.

Narciso Santos Yanguas......

Filosofía y paganismo en las postrimerías del Imperio Romano de Occidente. El caso del cónsul Mesio Febo Severo.

Rafael González Fernández y Miguel Pablo Sancho Gómez.

Dinámicas identitarias en el Mundo Actual: la religión como identidad frente al otro.

Rafael Ruiz Andrés y Francisco Javier Fernández Vallina.

El patrimonio fenicio-púnico. Claves para su socialización, puesta en valor y uso didáctico.

Helena Jiménez Vialás.

¿Cómo se enseña la llustración en $22^{\circ}$ de Bachillerato? Un análisis de los libros de texto, sus contenidos y la cuestión de género.

Helena Rausell Guillot..... 109

The Role of Local History in Elementary and Secondary Schools in Slovenia: An Evaluation of the Centre for School and Outdoor Education.

Danijela Trškan

Reseñas

Richardson, S. y Garfinkle, S. (eds.) (2016). Scholarship and Inquiry in the Ancient Near East (=Journal of Ancient Near Eastern History special issue, vol. 2/2, 2015) Berlin: de Gruyter. 179 págs.

Juan Álvarez García.

Guldi, J. y Armitage, D. (2016). Manifiesto por la Historia (traducción de Galmarini, M. A. The History Manifesto, 2014). Madrid: Editorial Alianza. 292 págs.

Juan Jesús Botí Hernández y David Omar Sáez Giménez.....

Normas de publicación/Publishing rules 



\title{
Dinámicas identitarias en el Mundo Actual: la religión como identidad frente al otro
}

\author{
Identity dynamics and Current History: Religion and Otherness
}

Rafael Ruiz Andrés ${ }^{1}$
I.U. Ciencias de las Religiones, Universidad Complutense

Francisco Javier Fernández Vallina²

I.U. Ciencias de las Religiones, Universidad Complutense

Recibido: 29/12/2016

Aceptado: 03/03/2017

Para citar este artículo: Ruiz Andrés, R., y Fernández Vallina, F. J. (2017). Dinámicas identitarias en el Mundo Actual: la religión como identidad frente al otro. Panta Rei. Revista Digital de Ciencia y Didáctica de la Historia, 71-83.

ISSNe: 2386-8864

DOI: $10.6018 /$ pantarei/2017/5

\begin{abstract}
Resumen
Los procesos experimentados por la modernidad y la posmodernidad han ido resquebrajando los discursos utilizados para la configuración identitaria. Si en un pasado cercano las ideologías y las creencias eran utilizadas como base de las identidades, los acontecimientos de los últimos años (muy especialmente el 11S) nos fuerzan a reflexionar sobre el nuevo rostro del mundo. Tras el descrédito de las identidades históricas, surge una pugna por la definición identitaria en la que el factor religioso juega un papel fundamental. A modo de conclusión se expone una reflexión sobre cómo poder vivir en esta búsqueda identitaria sin convertir a la identidad, especialmente la religiosa, en una trinchera frente al otro.
\end{abstract}

\section{Palabras clave}

Estudios sobre religión, Historia Social, Política, Civilización Occidental, Conflicto Religioso.

\begin{abstract}
The Modernity and Posmodernity processes have deeply damaged the identity configuration discourses. Ideologies and beliefs were used in the historical tradition as the basis of identities. However, the recent events (especially 11S) force us to reflect on the new face of the world and its particular dynamics. After the historical identities discredit, a struggle between different posibilities of cultural identity arises: a process in which the religious factor plays a fundamental role. Finally, we will think about living in this identity search without converting our self-definitions, especially religious identity, into a trench against the other.
\end{abstract}

1 Para contactar con este autor: Rafael Ruiz Andrés. Becario del Programa de Formación del Profesorado Universitario (FPU) del Ministerio de Educación, Cultura y Deporte. Referencia: FPU14/05460. Instituto Universitario de Ciencias de las Religiones - Universidad Complutense de Madrid. rafaru01@ucm.es.

2 Para contactar con este autor: Francisco Javier Fernández Vallina. Instituto Universitario de Ciencias de las Religiones - Universidad Complutense de Madrid. fjvallin@filol.ucm.es. 


\section{Keywords}

Religion Studies, Social History, Politics, Western Civilization, Religious Conflict.

\section{Introducción}

Hubo un tiempo en que la pregunta ¿quién soy? hallaba su respuesta en las condiciones inherentes a tu lugar de nacimiento. A la cosmovisión inveterada de la tradición se ligaba un horizonte de sentido que se abría ante los ojos del individuo (Taylor, 1996). Sin embargo, el ocaso del siglo XX ha terminado por resquebrajar las soluciones, dejando intacta la pregunta: ¿Quién soy yo? La fuerza de esta cuestión resuena en la actualidad doblemente, multiplicada por el eco que genera el solar yermo y vacío de la posmodernidad. A ciegas, el individuo trata de seguir generando soluciones al dilema de la existencia. En un mundo globalizado y tecnificado, aún estas preguntas no encuentran una respuesta válida en Google y las personas deben ensayar soluciones que puedan ir colmando la brecha existencial abierta. No todo se puede solucionar tecleando ${ }^{3}$.

La configuración de la identidad constituye uno de estos ensayos existenciales que en los albores del siglo XXI parece cobrar inusitada fuerza. Este será el propósito del artículo, estudiar el auge del fenómeno identitario centrándonos en un caso concreto: el papel que juegan las religiones para la definición de la identidad en nuestras sociedades secularizadas del Atlántico Norte y los múltiples dilemas planteados en el espacio religioso por la era de las identidades.

\section{De la firmeza de las creencias a la intemperie de la duda}

La búsqueda de la identidad es caracterizada, básicamente, como una búsqueda por dotarse de 'ser'. Una dinámica que emerge drásticamente en la actualidad debido a que precisamente las respuestas de las que nos habíamos servido, las 'creencias', se muestran exhaustas y agotadas.

Para Ortega, los pensamientos son ideas fútiles que tenemos, comprobamos y verificamos. Frente a las ideas que se poseen se erigen otras ideas, las creencias, cuya raigambre en nuestras vidas las convierten en una suerte de escenario indispensable para nuestra particular obra de teatro vital. Y si las ideas-pensamientos los tenemos, los poseemos, las 'creencias' son las ideas que somos (Ortega y Gasset, 2010, p. 2). El concepto de 'creencia' del filósofo español muestra toda su luz combinándolo con otro vocablo extraído de la reflexión orteguiana sobre la historia: 'fe social', es decir, el espíritu de una época. Tal y como señala Ortega, la 'fe social' se caracteriza por ser "una opinión colectiva, y cuando algo es opinión colectiva o social es una realidad independiente de los individuos, que está fuera de éstos como las piedras del paisaje, y con la cual los individuos tienen que contar quieran o no" (Ortega, 2007, p. 5). La aproximación a aquellos principios en torno a los cuales se identifique el grueso de una sociedad, nos estará en cierto modo hablando de esa misma sociedad.

Y, continuando con la introducción, podemos afirmar que hubo un tiempo en el que esta 'fe social' estuvo marcada profundamente por las 'creencias', de donde se extraían las respuestas a las cuestiones existenciales. Unas creencias en las que se 'está' y que condicionan tu ser. Como ya ha sido señalado por múltiples investigadores de la talla de K. Löwith (2007) en la presentación histórica existe una continuidad clara entre una era de las creencias religiosas que caracteriza a esa confesionalización de Europa durante el siglo XVI y la era de las creencias-ideologías durante los siglos XIX-XX: en todas ellas se 'está'. El historiador G. Corm (2007) nos muestra las pistas a través

3 Aunque se puede observar en Google Trends cómo la pregunta "Who am I?" ha ido creciendo desde que se tiene registro de la búsqueda en Google (desde el 2004) hasta la actualidad, alcanzando su punto máximo en abril de 2015: https://www.google.es/trends/explore?date=all\&q=quien\%20soy [Consultado el 20 de agosto de 2016]. 
de las cuales podemos rastrear la huella de continuidad entre las inquisiciones y las Gestapo-KGB, los pogromos y las purgas, los paraísos celestiales o los mundanos cielos del proletariado.

El hecho de ser arrojado a un mundo con unos principios fijos e inmutables, cuya máxima expresión es la tradición, marca el desarrollo existencial del individuo, puesto que las características del nacimiento condicionaban prácticamente todo el abanico de opciones vitales en las que podías moverte con seguridad (Hervieu-Léger, 2005). El nacimiento en la Castilla del XVI te hacia súbdito del Rey Católico, ligado a una parroquia que será el centro de tu vida y nacido en una Europa más comúnmente conocida como la Cristiandad; el contexto del París de 1848 te liga al inveterado solar de Francia, con todos los mitos nacionales y revolucionarios; tu infancia en un Kuhle Wampe (suburbio) berlinés te hace contemplarte inmerso en una lucha de clases, en una dinámica de un partido y con unos objetivos históricos concretos. De este modo, las dinámicas teológico-políticas de las creencias fueron sucedidas por las trayectorias político-teológicas de las ideologías. Las teologías-políticas y las políticas-teológicas te señalaban el origen, el camino, y la meta. Pero esta tierra firme de las creencias, dejada ya atrás de nuestro horizonte vital, no constituye el suelo que ahorma nuestros pies.

Si nos encontramos en la huida del mundo de las creencias, y las simples ideas no pueden constituir su correlato. ¿Hacia dónde estamos navegando? Siguiendo a Ortega y Gasset, las 'ideas' de ninguna manera son el contrapeso de las 'creencias'. Éstas necesitan de una 'alteridad' más existencial y radical, la duda: "La duda nos arroja ante lo dudoso, ante una realidad tan realidad como la fundada en la creencia, pero que es ella ambigua, bicéfala, inestable, frente a la cual no sabemos a qué atenernos ni qué hacer" (Ortega y Gasset, 2010, p. 13).

La tierra firme de las respuestas que aparecían ante nosotros como creencias comenzó a resquebrajarse con el terremoto de la duda, cuyo pórtico preside Descartes como símbolo de la crisis de la Conciencia Europea que se experimenta entre 1680-1715 (Hazard, 1988). Desde ese hito, un número mayor de personas han ido cogiendo su billete del barco 'de la duda' para abandonar el mundo de creencias firmes y sólidas y lanzarse a la intemperie, a alta mar. Sin embargo, el billete al mar de la duda sólo fue adquirido por una escueta élite hasta los albores del siglo XX. El transcurso del denominado corto siglo XX (Hobsbawn, 1998) ha ido lanzado a un número creciente de individuos al mar de la duda. Una centuria que tuvo como último gran estertor la construcción de un muro, el de Berlín, que señalaba claramente el límite entre dos modos de 'estar' en el mundo, entre dos herencias, entre dos posibilidades de 'ser' bajo el amparo de la OTAN o del Pacto de Varsovia. Pero desde 1989, tampoco estos dos modos de 'ser' son ya posibles. La caída de este muro parece haber trazado una pared de fuego entre la tierra de las creencias y los mares de la duda. Una pared de fuego que impide la vuelta a la tierra firme y nos fuerza a reflexionar sobre cómo sobrevivir a la intemperie. En este contexto emerge el ensayo de las identidades.

\section{El mar de las dudas abierto tras la caída del Muro}

¿Cómo se arriba al nuevo mar de la pugna identitaria? La progresiva sustitución de las cosmovisiones centradas en la ideología-creencia por el mundo de la duda, en el cual se están explorando las identidades, no se produce en una jornada o en un par de años. Podemos ver su progresiva irrupción desde el Romanticismo del siglo XIX de una tendencia basada en la justificación existencial por la vía sentimental y en la construcción del individuo con los parámetros que la racionalidad de las Luces había dejado arrinconados en la sombra. No por casualidad, el Romanticismo también es señalado como el primer gran movimiento de exaltación del individuo (Dalmau, 2012), así como la época histórica en la que se populariza en el imaginario colectivo un fenómeno identitario que ha marcado con excepcional fuerza las dos últimas centurias: la nación. (Taylor, 2006) Una tendencia ahondada en la dulce agonía de la década de los 20 del siglo pasado pero no generalizada hasta los años 60-70, donde el racionalismo de la eficiencia, tocado tras Auschwitz empieza a ceder paso a una dinámica expresionista: del sentimiento, de la sexualidad, 
de la libertad (Hobsbawn, 1998).

Paralelamente, el descubrimiento de un Tercer Mundo, término acuñado en 1952 por Alfred Sauvy, rasgaba la división binaria de la dominación activa y compartida del mundo que se había impuesto tras la Segunda Guerra Mundial. Todo este proceso alcanza su culmen con las posibilidades abiertas por la posmodernidad desde que en 1979 Lyotard presentara su escrito ¿Qué es la posmodernidad? La posmodernidad nos alerta del adentramiento en el mar de la duda. En palabras de S. Charles en el prólogo al libro de G. Lipovetsky:

La posmodernidad representa el momento histórico concreto en el que todas las trabas institucionales que obstaculizaban la emancipación individual se resquebrajan y desaparecen, dando lugar a la manifestación de deseos personales, la realización individual, la autoestima. Las grandes estructuras socializadoras pierden su autoridad, las grandes ideologías dejan de ser vehículos, los proyectos históricos ya no movilizan, el campo social ya no es más que la prolongación de la esfera privada: ha llegado la era del vacío pero sin tragedias ni apocalipsis (2006, pp. 23-24).

Evidentemente estamos ante un proceso que no se hizo en un día. Pero hubo un día en que cayó un muro: 9 de Noviembre de 1989. Y con él se derrumbó toda una manera de 'estar' en la historia. La caída del Muro coincide con el progresivo descrédito de las creencias en diferentes espacios del orbe: las Iglesias se despueblan en Europa, el socialismo árabe se sume en una serie de crisis que le llevaron hasta los vientos de las Primaveras y el marxismo o cualquier alternativa al capitalismo global era presentado como mera entelequia, tal y como había supuesto la posmodernidad. El solar abierto en el momento dio lugar a todo un sinfín de teorizaciones sobre el futuro bajo esa pregunta ¿qué sucederá a este fin histórico? ¿Volveremos a encontrar una tierra firme en la que descansar nuestros pies? En este punto, surgen dos hipotéticos mapas para navegar, sin duda extremos, casi caricaturescos. Por un lado nos encontramos la tesis de Fukuyama sobre el Fin de la Historia (1989) en la que según el autor, esta sería la época del reinado absoluto del liberalismo y de la técnica científica que acabará con cualquier pugna ideológica. En 1993 (y posteriormente en su libro de 1996), como respuesta, Huntington (2009) hablará del Choque de Civilizaciones: el modo de 'estar' en el espacio geopolítico post-Guerra Fría se caracterizaría, esencialmente, por la pugna entre los diferentes espacios civilizatorios-culturales. Según D. Lyon el Choque de las Civilizaciones supone:

(...) una visión alternativa a la de Fukuyama [que] considera que el futuro es una olla a presión positiva a punto de explotar por los conflictos de su contenido (...) Pero [Huntington] insiste en que lo más significativo de todo son las diferencias religiosas, que en la actualidad constituyen el medio básico de motivación y movilización (2010, p. 96).

Ambas, en cierto modo han confirmado parte de sus postulados: no porque se hayan cumplido en su totalidad, sino porque han encontrado unas aguas donde liberar su pugna: la identidad. Ni la historia ha finalizado, ni podemos hablar de una geopolítica basada en civilizaciones (un término simplista que nos oculta una mayor complejidad de las relaciones internacionales). Sin embargo, en la identidad podemos contemplar el fin de un modo de estar en la historia, aquel basado en la creencia-ideología. En la identidad podemos contemplar, paralelamente, la irrupción de dinámicas identitarias, de apariencia muy similar a las civilizaciones, que explican parte de los conflictos actuales, especialmente aquellos que se están librando como acción-reacción del fenómeno ambiguamente denominado como 'terrorismo global'. Más allá del Fin de la Historia y del Choque de Civilizaciones hoy nos adentramos en el mar de las dudas, del no-ser que busca dotarse de ser en las aguas de las identidades. 


\section{4. ¿Por qué el mar de las dudas se torna en el agua de las identidades?}

Hemos hablado de cómo la caída del Muro implica el final de una forma de 'estar', el final de una modernidad marcada por la creencia-ideología, y nos aproxima hacia una nueva etapa histórica marcada por las identidades. Pero ¿qué es la identidad?

La Real Academia Española (RAE) entiende por identidad "un conjunto de rasgos propios de un individuo o de una colectividad que los caracterizan frente a los demás". Su origen etimológico se compone de los términos latinos 'idem' y 'entitas' (Jáuregui y Méndez, 2005, p. 1), 'el mismo ser' o lo que es lo mismo, hablar de identidad es hablar del 'ser mismo'. En el mundo actual cada día en menor medida podemos hablar de condiciones dadas de antemano. El hecho de nacer en Burgos, París, Berlín, Río de Janeiro o El Cairo conlleva progresivamente menos características determinantes sobre quién debe ser ese individuo y de qué cosmovisión va a participar; en el mundo actual vivimos en medio de una carencia de ser dado y prefijado que hace de la búsqueda del propio ser una de las dinámicas esenciales de funcionamiento. De hecho, la caída del Muro significa, en cierta medida, el triunfo de dos dinámicas anteriores que continúan resquebrajando esa idea del ser dado y prefijado: la globalización y el individualismo, dos momentos de la modernización reflexiva según U. Beck (2009). Parece una absoluta contradicción. A medida que se amplía el marco-mundo, la globalización, se ha ido generando una tendencia de exaltación de la partícula más minúscula de la sociedad, el propio individuo (lo indivisible).

La posmodernidad y la globalización han favorecido la relativización de cualquier verdad, de cualquier discurso de creencia-ideología dado de antemano. El individualismo, por su parte, ha invertido la respuesta anteriormente dada por la colectividad al individuo: es ahora el individuo el que tiene que generar las respuestas que satisfagan a su propio desarrollo personal, construyéndolas en términos expresionistas. No obstante, los tres, posmodernidad, globalización e individualismo, han supuesto tres grietas en el 'ser' de los pueblos que han favorecido, paradójicamente, la búsqueda actual casi obsesiva por la identidad, por respuestas ciertas a la pregunta ¿quién soy? Una pregunta ahora desplazada desde la tradición, la comunidad o el pueblo hacia el individuo dado que estos procesos experimentados en el siglo XX "han terminado por desintegrar las antiguas pautas por las que se regían las relaciones sociales entre los seres humanos y, con ella, la ruptura de los vínculos entre las generaciones, es decir, entre pasado y presente" (Hobsbawn 1998, pp. 23-25). Como señala B.-Ch. Han "La respuesta a esta cuestión "nunca ha sido tan efímera como ahora. Pero no solo esta es efímera, sino también lo es el mundo en cuanto tal. Nada es constante y duradero. Ante esta falta de ser surgen el nerviosismo y la intranquilidad" (2010, p. 46).

Nerviosismo e intranquilidad que favorecen la búsqueda obsesiva del hecho diferencial que justifica tu 'ser' en un mundo cada vez más melting pot. Además, más allá de este ensayo teórico, vemos día tras día la búsqueda de la diferencia a través del último perfume y su fragancia exclusiva o de una prenda con la que realmente nos sentiremos nosotros mismos. Y es que, en definitiva, el 'sé tú mismo', la mismidad, se ha convertido en el gran proyecto de las sociedades posmodernas, en el gran proyecto de supervivencia a la intemperie. Nosotros, insertos en esta búsqueda de lo que nos define, lo que nos marca, nos sumergimos en el mundo de las identidades para buscar el añorado aroma de la tierra firme perdida.

Si veíamos que en las creencias-ideologías la base era el 'estar', se 'estaba' en ellas, en la identidad contemplamos un ser que busca dotarse de 'ser'. Un ser que desea 'ser' diferente en medio de la masa humana que hemos descubierto más homogénea de lo que pensábamos (o deseábamos) gracias a los procesos globales. La era de la identidad es, en definitiva, una búsqueda de las esencias cuando no existe una esencia global. Sin embargo, es lógico que nos surja la pregunta ¿Hasta qué punto esta construcción de las identidades se presenta como un proceso pacífico de definición personal, basado en cuestiones superfluas como prendas o perfumes? ¿O, por el contrario, este proceso puede derivar en una pugna de las identidades? En este punto debemos volver a la definición de la identidad dada por la RAE. 


\section{Religión como guía para náufragos en alta mar}

Tal y como hemos observado en la definición aportada por la RAE, y como casi todos los analistas señalan, la búsqueda de la identidad se realiza siempre en función de las características del otro, bajo mi mirada del otro y la mirada del otro sobre mí. En su obra Las religiones en el siglo $X X I$ afirma el historiador $\mathrm{G}$. Corm:

La identidad funciona en referencia a un polo negativo: la visión de otro diferente, si no enemigo. Por eso, todo sistema de valores que estructura una identidad es al mismo tiempo un componente esencial del sistema de poder que organiza el orden interior de la sociedad y decide sobre la guerra o la paz con una sociedad vecina diferente (2007, p. 63).

En este sentido, para la construcción identitaria debemos bucear en los denominados factores de identidad 'fuerte', entre los que se han destacado la sangre, el territorio, la comunidad etnolingüística y la religión (Nussbaum, 2013, pp. 32-22).

Vamos a centrar nuestra mirada en el factor religioso. ¿Qué aportan las religiones a la identidad?

- Una visión unitaria y coherente de la existencia a través de un conjunto de respuestas al origen y al final, cosmología y escatología.

- Un conjunto de prácticas periódicas (diarias, semanales, fiestas de especial importancia) que dotan de sentido al transcurso rutinario de la existencia. Son tiempos sagrados que irrumpen y orientan la profanidad del día a día y sus labores.

- Un corpus ético-moral, normas de comportamiento concretas.

- Y, por último, sentido de pertenencia a una comunidad (Iglesia, Umma, Shanga...).

No podemos olvidar que junto a todos los procesos señalados hasta el momento, las sociedades del Atlántico Norte han experimentado un fuerte proceso de secularización durante el siglo XX. Este hecho vuelca nuestro horizonte vital en un Marco Inmanente o en una Estructura de Mundo Cerrado (Taylor, 2015) que prácticamente invalida los dos primeros puntos para la construcción identitaria desde la religión, más relacionados con una trascendencia que se ha tornado intrascendente en la vida rutinaria moderna. En cuanto al tercer punto -el corpus ético-moral- ha ido secularizándose paralelamente con la sociedad. Aunque lo que consideramos valores éticos-morales posean un origen claramente cristiano, las sociedades democráticas han ido generando una moral autónoma sin necesidad de referencia divina. No obstante, y ante las cenizas de sus proyectos paralelos civiles, no podemos decir lo mismo del sentido de comunidad religiosa: es el aspecto de la comunidad perdida y añorada uno de los que, precisamente, adquiere un nuevo brío en la época en la que habitamos. Esta renovada presencia del factor religioso en el contexto internacional se puede contemplar en el cambio de paradigma en la obra de P. Berger, uno de los sociólogos de la religión más reputados. En los años sesenta, defendía que:

Quizá por primera vez en la historia las legitimaciones religiosas del mundo han perdido su plausibilidad, no solo para unos pocos intelectuales y otros individuos marginales, sino también para grandes masas de sociedades enteras. Esto inició una crisis aguda que no solo afectó la nomización de las grandes instituciones sociales, sino también la de las biografías individuales (Berger, 1969, p. 155).

La secularización era un hecho innegable que llevaría, antes o después, a la eliminación de las religiones. Sin embargo, desde los años noventa, y muy especialmente en su última obra Los numerosos altares de la modernidad (2016), Berger analiza cómo los discursos e identidades seculares y religiosos se entrelazan de maneras más complejas. Del mismo modo, J, Casanova en Public Religions in Modern World (1994) hace un pormenorizado estudio de esta vuelta del factor religioso a la escena pública en diferentes escenarios mundiales (e incluso en contextos 
supuestamente secularizados).

Y es que la comunidad religiosa presenta, de un lado, la fuerza de la tradición: el individuo que se define como adscrito a una tradición religiosa acepta el linaje creyente que representa, dotando a su vida del sentido que esta vinculación conlleva. Además, por otra parte, las comunidades religiosas, muy especialmente de las dos religiones más numerosas de la tierra, el cristianismo y el Islam, proporcionan pertenencia a una comunidad global y transnacional en un momento de clara crisis de legitimidad y debilidad de los Estados-nación y de los partidos-Iglesia, en claro retroceso durante las últimas décadas del siglo XX. En definitiva, y paradójicamente a la teoría de la secularización, "la elección de remitirse, de manera voluntaria, a la autoridad de una tradición, e incorporarse subjetivamente a la continuidad de un linaje, constituye una de las modalidades posibles de la construcción postradicional de la identidad del yo, entre muchas otras que ponen en juego la afectividad de los individuos y se alimentan de sus aspiraciones comunitarias, sus recuerdos y sus nostalgias" (Hervieu-Léger, 2005, p. 271).

Siguiendo esta explicación, podemos contemplar dos construcciones concretas de identidad que en la actualidad de las sociedades del Atlántico Norte se están valiendo de cuestiones religiosas para constituirse: una construcción positiva tanto en cuanto afirmación de una identidad religiosa (la identidad judeocristiana) y una construcción negativa, tanto en cuanto oposición a una identidad religiosa (el antiislamismo).

\section{El faro de la identidad judeocristiana}

La secularización ha desplegado todo su potencial en el campo de la práctica religiosa. Durante la segunda mitad del siglo XX, la mayoría de las sociedades del Atlántico-Norte, muy especialmente las europeas, han experimentado un drástico descenso en el número de personas que participan activamente de sus creencias religiosas. En el caso concreto español en 1978 el $61.2 \%$ de la población era católico practicante, mientras que en el 2017 esta cifra es apenas del $16 \%$ (Centro de Investigaciones Sociológicas - CIS, 2017). Sin embargo, en cuanto a la afirmación identitaria, la gran mayoría de los europeos continúan considerándose cristianos. Más aún, la mayoría de los textos constitucionales o de las estructuras estatales prevén cierta preeminencia para la Iglesia cristiana 'tradicional' de la nación. Este desacompasamiento entre el clásico binomio creencia-pertenencia ha sido traducido sociológicamente con dos conceptos: belongers not believers y 'religión vicaria'.

Belongers not believers es un término acuñado por D. Hervieu Léger para designar a aquellos individuos que, sin ser practicantes de una religión, se consideran a sí mismos como pertenecientes a la misma. Se caracterizan por la posesión de un concepto de lo "divino" que se encuentra vacío o difuminado de un contenido real y no tiene incidencias en la vida (Estrada, 2015, p. 57). Sin embargo, el concepto de lo "religioso", para este mismo sector, se ha ido llenando de toda una serie de connotaciones identitarias que sirven como factor de construcción de la personalidad frente a los diferentes marasmos que proceden de un mundo interconectado y globalizado. Busquemos las huellas de este fenómeno en el estudio sobre religión del CIS del 2008, la última investigación en profundidad realizada por esta institución sobre el tema religioso.

El $73.1 \%$ de la población española se denomina católico en 2008. Sin embargo, sólo el $21.8 \%$ de la población reza o práctica los cultos propios de su fe una o más veces a la semana frente a un $35.5 \%$ que no realiza plegarias u otros ritos nunca. El $73 \%$ declara que no participa en actividades de compromiso religioso aparte de asistir a las festividades preceptivas, frente a un $5.2 \%$ que suman los que afirman hacerlo casi todas las semanas, todas las semanas o varias veces a la semana. EI dato más esclarecedor puede ser que el 36. $2 \%$ de la población española se declara seguidor de una religión pero no preocupado por lo espiritual ni lo sobrenatural, frente a un $20.1 \%$ que se declara religioso y espiritual. Posiblemente sea una de las muestras más fehacientes del estrato belonger not believer de la sociedad española. Los creyentes sin preocupación por la creencia-contenido, sino por la denominación-continente religiosa. Paradójicamente, la desertización de las Iglesias 
se ha ido acompañando de un proceso de revitalización de las religiosidades populares (romerías, procesiones...). Si en otro tiempo tenían un significado esencialmente trascendente, a día de hoy se han convertido por un lado en afirmaciones identitarias y culturales de las colectividades locales, y por otro lado, en un fenómeno turístico de masas.

G. Davie propone, como complemento a esta realidad del perteneciente no creyente, la existencia de una 'religión vicaria' (2006, pp. 277-278). Un credo religioso, de este modo, se sitúa más íntimamente ligado al Estado por medio de un desarrollo histórico compartido (ser un 'verdadero' sueco significa ser miembro de la Iglesia de Suecia como ser un 'verdadero' español se traduciría por estar vinculado de algún modo a la tradición católica). En la esencia histórica de dicho Estado se encontraría el fermento religioso de la confesión en cuestión, que en la actualidad se traduce en una serie de ventajas jurídicas (independientemente del seguimiento de la religión por parte de la sociedad). Este hecho es aceptado por un amplio porcentaje de la población, creyente o no, que ve en la relación particular del Estado con dicha confesión la conservación de una identidad propia de la nación.

Como ejemplos paradigmáticos nos encontramos la situación sueca y británica. ${ }^{4}$ Suecia es actualmente uno de los países más secularizados del mundo (un índice de asistencia a los oficios religiosos por los suelos -en torno al $5 \%$ semanal- junto a una afirmación de la no creencia en Dios que supera el $50 \%$ ). Frente a esta realidad sociológica, en el Instrumento de Gobierno de Suecia de 1976, vigente a día de hoy, se establece una mención específica en el artículo 2.4 que dota de entidad jurídica a las decisiones adoptadas por la Iglesia de Suecia. Igualmente, Reino Unido posee una sociedad profundamente secularizada (la no creencia en Dios es sostenida por el $44.6 \%$ de la población). Sin embargo, este hecho no es óbice para que la jefa del Estado se intitule desde 1534 con el título de Gobernadora Suprema de la Iglesia de Inglaterra.

Más explícitas son las menciones a un credo concreto en los ordenamientos jurídicos de Dinamarca o Irlanda. En la constitución danesa de 1953, el Artículo 4 suscribe "La Iglesia evangélica luterana es la Iglesia nacional danesa y gozará, como tal, del apoyo del Estado"; mientras que el preámbulo del texto irlandés de 1937 comienza invocando el "nombre de la Santísima Trinidad, de quien procede toda autoridad y a quien revierten como destino ultimo todas las acciones tanto de los Estados como de los hombres". En España, continúa aún el debate por el polémico artículo 16.3 de la Constitución española en el que se afirma: "Ninguna confesión tendrá carácter estatal. Los poderes públicos tendrán en cuenta las creencias religiosas de la sociedad española y mantendrán las consiguientes relaciones de cooperación con la Iglesia Católica y las demás confesiones". Aunque durante el siglo XX en la situación entre las diferentes Iglesias y los Estados se han ido abriendo brechas (las legislaciones sobre la ley del aborto o del matrimonio homosexual en España durante el mandato del PSOE, la definitiva separación de la Iglesia-Estado en Suecia entre el 1999 y el 2000 o la victoria en el referéndum de la ley del matrimonio homosexual en Irlanda en 2015) también es cierto que en la mayoría de los países continúan las prerrogativas a favor de una confesión y que en este punto -la situación jurídica de la Iglesia en el Estado- se produce uno de los debates que más polarización genera entre la sociedad civil.

Como hemos observado, el privilegio (simbólico o real) a una confesión, la tradicional, es una práctica común en las naciones europeas que, aunque respetuosas con la diferencia, siguen potenciando una supuesta homogeneidad social y cultural. En palabras de la profesora M. Nussbaum:

Aun así, [las naciones de Europa] comparten un interés por la homogeneidad que las lleva a cometer ciertos errores preocupantes en sus argumentos públicos. Si esos países fueran islas aisladas en medio de un territorio inexplorado, como las colonias americanas originales se veían a sí mismas, sería más comprensible que buscaran un espacio separado en el que asociarse con gentes iguales o parecidas a ellos [...] (2013, p. 170).

4 Datos de 2008 tomados de GESIS Data Archive for the Social Sciences (2012). 
Las dos realidades sociológicas presentadas (belongers not believers y la 'religión vicaria') favorecen la expansión en obras académicas y divulgativas del término 'civilización judeocristiana' tanto en Europa como en Norteamérica. El concepto de judeocristianismo se erige, de este modo, como una suerte de faro que brinda supuestos destellos de luz al desconcierto identitario, una referencia de cuasi obligada mención en cualquier texto de análisis sobre la 'civilización occidental'. Este término, nacido en el siglo XIX y popularizado en la segunda mitad del siglo XX, trata de unir a un vago concepto de civilización cristiana lo que Auschwitch había intentado erradicar, la herencia judía. Sin embargo, en el judeocristianismo hay un gran ausente: el islam. Y el problema deriva principalmente de que estos hechos de una construcción, en principio de reafirmación identitaria, se puedan utilizar en un conflicto de identidades contra ese gran ausente, cada día más presente en los medios de comunicación.

\section{La armada frente a lo islámico}

Con la caída de la URSS en 1991 y muy significativamente con la vorágine de atentados reclamados como yihadistas desde el 11 de Septiembre de 2001, el gran otro de las sociedades del Atlántico-Norte ya no es lo 'soviético', sino lo 'islámico'. El alter ego ya no se presenta a sí mismo con atributos de la liberación de clase, del colectivismo económico, sino con ropajes religiosos. El especialista en terrorismo D. C. Rapoport ha clasificado en cuatro periodos a la historia del terrorismo, dependiendo de la inspiración de la que se nutre: anarquista (siglo XIX), los movimientos descolonizadores (tras la I Guerra Mundial), extrema izquierda (últimas décadas del siglo XX ) y de base religiosa (en la actualidad) (Martín, 2015).

El origen de esta cuarta oleada terrorista se encuentra en la creación del Frente Mundial para la Yihad contra Judíos y Cruzados por parte de Bin Laden en 1998. Este grupo, que se define como esencialmente religioso (Yihad), se contrapone a un otro religioso (judíos y cruzados) y su inspiración se halla en una supuesta imagen de Dios vengador. Como el promotor, Bin Laden, afirmó en Octubre de 2001 tras los atentados del World Trade Center: "Dios ha enviado un ataque sobre Estados Unidos y ha destruido varios de sus mayores edificios. Y observamos a América aterrorizada de norte a sur y de este a oeste, gracias a Dios". ${ }^{5}$ Paralelamente, desde la creación del Frente Mundial para la Yihad el enemigo ya no son los Grandes Satanes, Estados Unidos y la Unión Soviética, ateos, libertinos y materialistas. En la actualidad, los grupos yihadistas se presentan como defensores ante la vuelta de los cruzados: en la retórica del DAESH son continuas las comparaciones de la alianza internacional con un ejército de cruzados (Francois-Cerrah, 2015).

Estas declaraciones han encontrado una respuesta en líderes políticos que, a pesar de ser autoridades de estados laicos, no han dudado en utilizar el discurso de tintes religiosos para enconar los ánimos de las poblaciones. El propio Bush utilizó la palabra 'el mal' para referirse al terrorismo de cuño islámico un total de 199 veces en los discursos sobre política exterior entre Septiembre de 2001 y Marzo de 2002 (Black, 2004). Más recientemente, en la Navidad de 2015, el primer ministro británico, David Cameron realizaba paralelamente una declaración de identidad cristiana de Reino Unido: "Deberíamos reflexionar también sobre el hecho de que estas importantes raíces religiosas y los valores cristianos son el motivo por el que Gran Bretaña ha sido un hogar tan exitoso para las personas de todos los credos y para quienes no tienen ninguno" (R., 2015, párr. 8). Afirmación que combinó con el continuo elogio de las acciones militares realizadas por el ejército británico:

En este momento, nuestras valientes fuerzas armadas cumplen con su deber en todo el mundo: en los cielos de Irak y Siria, contra los terroristas que amenazan a esos países y nuestra seguridad en el hogar; en los mares del Mediterráneo, salvando a quienes intentan el peligroso viaje a Europa; y en el terreno, ayudando a llevar la estabilidad desde Afganistán a Sudán del Sur (R., 2015, párr. 5).

5 Recuperado de http://www.retoricas.com/2010/05/discurso-de-bin-laden-los-estados.html

Panta Rei (2017), 71 - 83 
Así pues, contemplamos como más allá de los fenómenos culturales internos (religión vicaria y belongers not believers) la definición identitaria con trazos religiosos encuentra un importante eco a ambas orillas de los conflictos geopolíticos actuales. Más aún, este hecho en las sociedades denominadas occidentales nos genera una cuestión incómoda ¿hasta qué punto la utilización de ecuaciones religiosas en sociedades considerablemente desconectadas del germen de la religiosidad servirá de pretexto para su descarada manipulación? ¿Hasta qué punto estos ropajes religiosos, vacíos interiormente, se dotarán de nuevas armas contra los 'otros', especialmente el gran otro islámico? La respuesta la encontramos en la expansión (en votos y afiliados) de un discurso que no toma tan explícitamente como Bush o Cameron las figuras religiosas. Éste se dota de un difuso y ambiguo concepto de civilización occidental, asimilada como 'civilización judeocristiana', tal y como se está predicando desde los estrados políticos en las últimas décadas, para llenar párrafos, mítines y panfletos contra un colectivo concreto: el musulmán. Es un uso de la religión que traiciona su propia etimología; un uso de lo religioso que, ante todo, sirve para 'desligar' colectivos humanos. Contemplemos tres ejemplos habituales en nuestros periódicos: la carrera presidencial de D. Trump, el Frente Nacional en Francia y el Pegida.

El recientemente nombrado presidente Trump, en su afán por recolectar aquel voto que no es directamente contrario a sus postulados, experimentó una conversión religiosa súbita (y no exenta de interés político). Bastan como ejemplos dos declaraciones. Trump afirmó en una entrevista el 9 de Marzo de 2016: "El Islam nos odia" (Schleifer, 2016, párr. 2). En otra entrevista, fechada el 20 de Mayo de 2016, apuntó que "los cristianos están siendo tratados de una manera horrible porque no tenemos nadie para representar a los cristianos. Créeme. Si yo me presento y gano, yo seré el mayor representante que los cristianos han tenido en mucho tiempo"(Brody, 2016).

En la otra ribera del Atántico, mientras el Pegida (patriotas europeos contra la islamización de Occidente) continúa abriendo franquicias y ganando adeptos en todo el continente, Marine Le Pen redactó un comunicado de prensa sobre el asesinato del sacerdote francés en julio de 2016 en el que señala:

La consternación es total. Un paso más ha sido dado por los bárbaros que reclaman esta ideología asesina, atacando a un lugar de culto de la Iglesia Católica y cometiendo tales atrocidades en los hombres y mujeres de paz. Ahora es el corazón de la identidad cultural de nuestra nación [cursivas añadidas] lo que ha sido intencionalmente herido (traducción propia) (Le Pen, 2016, párr. 2).

La religión, como definición positiva, está prácticamente ausente. Lo que predomina en el discurso son los instrumentos de la religión desligante, la utilización de vagos conceptos culturales (con una base sociológica empírica basada en la 'pertenencia sin creencia' y en la 'religión vicaria') que son utilizados para señalar la brecha existente entre dos cosmovisiones, dos identidades irreconciliables: la judeocristiana, moderna, occidental y democrática frente al mundo islámico, machista, intolerante, violento y atrasado. Es un nosotros contra un ellos, nuestra identidad contra su amenaza. Nótese que la ambigüedad de los conceptos forma un arma arrojadiza de gran importancia.

A estas declaraciones se suman cuestiones como el asunto del burka en Francia o la prohibición de la construcción de minaretes en Suiza, hechos que enfatizan la sensación de que la población migrante musulmana tiene permiso de residencia pero un más complicado acceso al estatus de ciudadano europeo. En definitiva, la categoría como ciudadano de segunda, como cuerpo extraño, como el gran 'otro' allana el camino para la conversión del colectivo musulmán en 'chivo expiatorio' al confirmarle como diferente del resto del conjunto social. Un chivo expiatorio donde redimir nuestro proyecto de modernidad. Como afirma el profesor Casanova: "es la práctica libre pública y colectiva del islam como una religión inmigrante lo que la mayoría de sociedades europeas encuentran difícil de tolerar, precisamente sobre la base de que el Islam es percibido como una religión esencialmente "no-europea" (Casanova 2007, p. 17). Y se retoma el discurso de Catilina, con nuevos actores: 
es el Islam el que tiene que ser expulsado, señalado, destruido para que nuestras democracias subsistan. Sin embargo, son las afirmaciones como las presentadas las que, desde dentro, están cuestionando y rasgando nuestros Estados sociales y de derecho.

\section{El dilema: construir nuevos muros o vivir en el mar de la intemperie identitaria}

El fin del Muro ha supuesto la agonía de un modo de 'estar' y de sentir la historia. El descrédito de las creencias y de las ideologías, la relativización de la verdad, la globalización y el individualismo han ido marcando los hitos de una nueva manera de 'ser' en la historia: el ser individual, posmoderno y global, que ha resultado ser un proyecto esencialmente vacío, puesto que su esencia se caracteriza por no tener ninguna esencia, por hallarse alejado de cualquier 'tierra firme'. Sin embargo, a pesar de los cambios, el horror vacui continúa presentándose como una dinámica históricamente operativa. Nos miramos al espejo y nos aterra no encontrar nada que nos defina, nada que nos diferencie de los otros miles de millones de nuestra Tierra. Nos encontramos solos en alta mar y a la vez rodeados de millones de polizones en la misma deriva. En este punto surge, como hemos observado, la llegada de la era de las identidades. Dos son las conclusiones principales de este artículo.

En primer lugar, la construcción de las identidades ha brindado nuevos campos a unos discursos religiosos que la secularización pretendía haber desarticulado. No obstante, debemos ser escrupulosos a la hora de acercarnos a estos fenómenos. La individualización ha favorecido múltiples formas de entender la religiosidad, generando una suerte de 'religión a la carta' (Bahamondes, 2013, pp. 47-48). En este sentido, entre la creencia y la no creencia se cuela un amplio espacio: las zonas intermedias. Y por su propia indefinición pueden ser utilizadas para lo que se convenga. Si bien es cierto que la secularización ha causado un hondo impacto en la práctica de las religiones, no ha sucedido lo mismo con la definición religiosa: numerosos occidentales no ven ningún problema en unir una definición identitaria religiosa con una práctica inexistente. Y es que, aunque ha sido obviado por muchos teóricos, las religiones no son simplemente creencias: la religión otorga pertenencia, factor de identidad fuerte. Además muchas de las religiones combinan un sentimiento identitario con una pertenencia globalizada, lo que constituyen dos claves de éxito en nuestra sociedad actual.

No obstante, el factor de identidad puede pasar de ser un rasgo de afirmación colectiva (civilización judeocristiana) a un arma en la guerra de las identidades (contra lo islámico). En este sentido, aunque las guerras de religiones suenan una cuestión lejana y atrasada, propias de otra etapa histórica, la gran pregunta es ¿Cuándo fueron las guerras entre religiones, conflictos bélicos exclusivamente entre creyentes y credos? ¿No han sido en la mayoría de las ocasiones excusas que ocultaban, tras los rasgos sagrados, otras motivaciones más mundanas? En nuestras sociedades secularizadas, un cristiano que no se preocupa en absoluto de las cuestiones doctrinales del cristianismo puede atrincherarse en la defensa de una identidad cristiana (en la que cree relativamente) para salvaguardar la esencia de lo que considera impertérrito. Como en tantas ocasiones, la creencia se queda en un segundo plano a la hora de los conflictos. Y la era secular no es una excepción.

En segundo lugar, ¿cuál es la salida a este círculo vicioso de ataques yihadistas y trincheras identitarias? Como afirma Z. Bauman: "vivir perpetuamente con el problema de la identidad sin resolver constituye la condición general de los hombres y mujeres contemporáneos en nuestro tipo de sociedad" (2009, p. 37). Ahí está el reto: en vivir a la intemperie identitaria, dentro de una etapa que ha llegado demasiado tarde para los dioses y demasiado pronto para el 'ser' (Heidegger, 1976, p. 21). Ensayar soluciones a nuestra constitución existencial sin blindarlas, sin hacer de ellas una nueva trinchera desde donde atacar y defenderse. Compartir nuestra condición de náufragos sin necesidad de alzar armadas. Vivir a la intemperie. Parece una solución precaria pero, por el momento, la única realmente compatible con las sociedades democráticas. Aceptar que tus identidades y las de los otros son meras construcciones, meros ensayos; no bloques confrontados, no civilizaciones. 
Si no aceptamos una flexibilidad identitaria nos enfrentamos a la resurrección de los muros, esta vez no en Berlín, sino en Ceuta, en Hungría o en México; todos ellos símbolos físicos de un único muro más grande, más amplio y más profundo que se está ya apuntalando entre las distintas identidades de mundos supuestamente distintos. Pero un muro, ante todo, ignorante que parece olvidar la nueva base sobre la que se yergue: las inestables aguas de alta mar.

\section{Bibliografía}

Bahamondes, L. (2013). El hecho religioso en clave posmoderna: de la secularización a la mutación. Santiago de Chile: Centro de Estudios Judaicos, Universidad de Chile - CISOC, Universidad Alberto Hurtado.

Bauman, Z. (2009). La posmodernidad y sus descontentos. Madrid: Akal.

Beck, U. (2009). El Dios personal. La individualización de la religión y el "espíritu del cosmopolitismo". Barcelona: Paidós.

Berger, P. (1969). El dosel sagrado. Elementos para una sociología de la religión. Buenos Aires: Amorrortu Editores.

Berger, P. (2016). Los numerosos altares de la modernidad. En busca de un paradigma para la religión en una época pluralista. Salamanca: Ediciones Sígueme.

Bin Laden, O. (2001). América aterrorizada. Recuperado de http://www.retoricas.com/ 2010/05/ discurso-de-bin-laden-los-estados.html

Black, A. E. (2004, Septiembre). With God on Our Side: Religion in George W. Bush's Foreign Policy Speeches. Presentado en el Annual Meeting of the American Political Science Association, Chicago, IL. Recuperado de http://www.ucs.louisiana.edu/ ras2777/relpol/bushreligion.PDF

Brody, D. (2016, 20 de mayo). Donald Trump Tells Brody File: As President 'I will be the greatest representative of the Christians they've had in a long time', CBN News Blog. Recuperado de http://blogs.cbn.com/thebrodyfile/archive/2015/05/20/donald-trump-tells-brody-file-aspresident-i-will.aspx?mobile=false.

Casanova, J. (1994). Public Religions in the Modern World. Chicago: University of Chicago Press.

Casanova, J. (2007). Dimensiones del pluralismo religioso. La inmigración y el nuevo pluralismo religioso. Una comparación Unión Europea/Estados Unidos. Revista CIDOB d'Affers Internationals, 77, 13-39. Recuperado de http://www.raco .cat/ index. php/revistacidob /article/ viewFile/69474/79708

Centro de Investigaciones Sociológicas (2008). Informe Religión (II) ISSP, Estudio n 2.776 (Oct.Dic. 2008). Recuperado de_http://www.cis.es/cis/opencm/ES/1 encuestas/ estudios/ver. isp?estudio $=103827$

Centro de Investigaciones Sociológicas (2017). Barómetro de Enero de 2017. Estudio $\mathrm{n}^{\circ} 3164$ (Ene. 2018). Recuperado de http://www.cis.es/cis/export/sites/default/-Archivos/Marginales $13160 \quad 3179 / 3164 /$ es3164 mar.pdf

Charles, S. (2006). El individualismo paradójico. Introducción al pensamiento de Gilles Lipovetsky. En G. Lipovetsky, Los tiempos hipermodernos (pp.13-49). Barcelona: Anagrama.

Corm, G. (2007). La cuestión religiosa en el siglo XXI. Madrid: Taurus.

Dalmau, M. (2012). El ocaso del pudor. Barcelona: Edhasa.

Davie, G. (2006). Religion in Europe in the 21st Century: The Factors to Take into Account. European Journal of Sociology, 47, 271-296. Recuperado de https://www.cambridge. org/core/journals/european-journal-of-sociology-archives-europeenne s-de-sociologie/ article/religion-in-europe-in-the-21st-century-the-factors-to-take-into-account/ 0E8E882C38B510A021EED11633A15F09

Estrada, J.A. (2015). ¿Qué decimos cuando hablamos de Dios? La fe en una cultura escéptica. Madrid: Trotta.

Francois-Cerrah, M. (2015, 18 de noviembre). Islamic State wants to divide the world into jihadists 
and crusaders. The Telegraph. Recuperado de http://www.telegraph.co.uk/ news/worldnews/ islamic-state/12002726/The-grey-zone-How-Isis-wants-to-divide-the-world-into-Muslims-an d-crusaders.html.

GESIS - Leibniz Institute for the Social Sciences, Cologne, Germany (2012). International Social Survey Programme, ISSP 2008 - Religion II Variable Report Documentation. Recuperado de http://zacat.gesis.org/webview/index/en/ZACAT/ZACAT.c.ZACA T/ISSP.d. 58/by-Year.d.69/ International-Social-Survey-Programme-2008-Religion-III-ISSP-2008-/fStu dy/ZA4950.

Han, B.-C. (2010). La sociedad del cansancio. Barcelona: Herder.

Hazard, P. (1988). La crisis de la conciencia europea (1680-1715). Madrid: Alianza.

Heidegger, M. (1976). Questions III et IV. Paris: Gallimard.

Hervieu-Léger, D. (2005). La religión hilo de memoria. Barcelona: Herder.

Hobsbawn, E. (1998). Historia del siglo XX. Buenos Aires: Crítica.

Huntington, S. (2009). El choque de civilizaciones y la reconfiguración del orden mundial. Barcelona: Paidós.

Jauregui, I. y Méndez, P. (2005). La identidad, el gran delirio de Occidente. Nómadas. Revista Crítica de Ciencias Sociales y Juridicas, 11. Recuperado de https://pendientedemigracion. ucm.es/info/nomadas/11/jauregui mendez.pdf

Le Pen, M. (2016, 26 de julio). Communiqué de Presse de Marine Le Pen. Sitio oficial del Frente Nacional. Recuperado de http://www.frontnational.com/2016/07/communique-de-presse-demarine-le-pen-6/.

Löwith, K. (2007). Historia del mundo y salvación: los presupuestos teológicos de la filosofía de la historia. Buenos Aires: Katz Editores.

Lyon, D. (2002). Jesús en Disneylandia. La religión en la posmodernidad. Madrid: Ediciones Cátedra.

Martín, M. A. (2015). Introducción. En Panorama Geopolítico de los Conflictos 2015. Madrid: Instituto Español de Estudios Estratégicos, Ministerio de Defensa. Recuperado de http://publicaciones. defensa.gob.es/.

Nussbaum, M. C. (2013). La nueva intolerancia religiosa. Cómo superar la política del miedo en una época de inseguridad. Barcelona: Paidós.

Ortega y Gasset, J. (2007). Historia como sistema. Madrid: Biblioteca Nueva.

Ortega y Gasset, J. (2010). Creer y pensar. Recuperado de www.omegalfa.es.

R. C-M (2015, 24 de diciembre). Cameron vuelve a defender las raíces cristianas en su mensaje de Navidad. La Gaceta. Recuperado de http://gaceta.es/noticias/cameron-vuelve-defenderraices-cristianas-mensaje-navidad-24122015-0949.

Schleifer, T. (2016, 10 de Marzo). Donald Trump: 'Creo que el Islam nos odia'. CNN. Recuperado de http://cnnespanol.cnn.com/2016/03/10/donald-trump-creo-que-el-islam-nos-odia.

Taylor, C. (1996). Identidad y reconocimiento. Revista internacional de filosofía política: RIFP, 7 , 10-19.

Taylor, C (2006). Las fuentes del yo. La construcción de la identidad moderna. Barcelona: Paidós.

Taylor, C (2015). La Era Secular, Tomo II. Barcelona: Gedisa. 


\section{Panta Rei}

PANTA REI es una revista digital de investigación orientada a la Historia y otras ciencias afines. Su principal objetivo es la transmisión del conocimiento científico, dando una oportunidad también a los jóvenes investigadores que quieren abrirse camino en el estudio de las ciencias humanas y sociales. Se compone de estudios originales relacionados con la disciplina histórica así como su didáctica y difusión. Las diferentes secciones que componen la revista son: artículos de investigación, entrevistas a profesionales, recensiones de monografías de actualidad y crónicas de congresos o eventos científicos relevantes.

Todos los artículos publicados son objeto de un proceso de revisión a cargo de un mínimo de dos evaluadores, que se consideran expertos en el ámbito temático del artículo propuesto. Nuestro deseo es poder ofrecer unos contenidos rigurosos, de calidad y de interés.

EI CEPOAT (Centro de Estudios del Próximo Oriente y la Antigüedad Tardía de la Universidad de Murcia) es la institución encargada de la coordinación y gestión de la revista, desde donde anualmente se lanzará la convocatoria para aquellos que estén interesados en publicar sus trabajos, siempre relacionados con la Historia, Arqueología, Historia del Arte, Didáctica de las Ciencias Sociales, etc.

PANTA REI is a digital journal focused on History and other sciences related to it. Its main objective is the transmission of scientific knowledge by giving also an opportunity to young researchers who want to make their way in the study of human and social sciences. It is composed by original studies related to History, as well as its didactics and promotion. The different sections of this journal are: research articles, interviews to professionals, recensions on monographs about current issues and reports about congresses or relevant scientific events.

All the articles published are subject to a revision process carried out by a minimum of two reviewers who are considered to be experts in the field of the article proposed. Our wish is to offer rigorous contents with quality and being of interest to the reader.

CEPOAT (Centre of Studies of the Middle East and Late Antiquity of the University of Murcia) is the institution in charge of the coordination and management of this journal. This is the centre from where the call for papers will be launched for all the people interested in publishing their papers, always related to History, Archeology, Art History, Didactics of the Social Sciences, etc. 


\section{Normas de Publicación}

El autor se compromete a enviar trabajos originales, que no se encuentren publicados en otras revistas ni en otros idiomas. Así mismo, el mismo artículo no podrá ser presentado en otras revistas mientras dure el proceso de evaluación.

\section{Envío y presentación de originales}

Los artículos se enviarán exclusivamente a través del correo electrónico a la dirección pantarei@um.es. Los textos serán enviados en formato DOC y las imágenes en formato JPEG o TIFF, y con un tamaño mínimo de 2000 px. Éstas no aparecerán incorporadas en el texto, sino enviadas en archivo aparte y correctamente numeradas según su posición en el texto. Junto al trabajo, se rellenará y enviará un documento aparte en el que se especifiquen los datos del autor siguiendo el modelo disponible en la página Web de la revista.

Para la redacción de los trabajos se tendrá en cuenta el Manual de la American Psychological Association, en su sexta edición. La extensión máxima de los trabajos será de 30 páginas. La tipografía será Arial 11, con interlineado sencillo y sin espacio alguno entre párrafos. El texto deberá ir justificado a ambos márgenes y sin sangría en los primeros párrafos. Los márgenes serán de $2,50 \mathrm{~cm}$. En los casos en los que fuera necesario incorporar notas, éstas irán a pie de página, enumeradas consecutivamente, con tipografía Arial 10, interlineado sencillo y justificadas a ambos márgenes.

Una información más detallada se encuentra disponible en la página http://www.um.es/cepoat/ pantarei.

\section{Proceso de valoración y evaluación}

Una vez recibidos los trabajos, la Revista realizará una primera valoración. Si el trabajo enviado se ajusta a las normas de presentación propuestas, la temática es coincidente con la línea editorial de la revista y posee la calidad científica necesaria, será remitido al consejo asesor para una primera evaluación. Si no es así en este primer paso se puede rechazar directamente los documentos que incumplan claramente la línea editorial.

Será el Consejo Asesor quien indique a la revista la originalidad, relevancia, estructura, redacción, aparato bibliográfico, etc. del trabajo enviado y, para ello, se designará a dos revisores expertos externos que evaluarán cada uno de los trabajos, que pueden formar parte (o no) de este Consejo Asesor. La selección de los revisores se ajustará a la temática y características metodológicas del trabajo. El nombre y filiación de los autores serán eliminados del trabajo para su revisión, así como los revisores actuarán de manera anónima y confidencial.

Los revisores deberán rellenar un informe de evaluación que centrará su atención en aspectos tales como características formales, originalidad y novedad de los trabajos, relevancia de las propuestas y los resultados, calidad metodológica y validez científica.

Una vez terminado el proceso se decidirá la aceptación o no de los mismos y su publicación en el número que sea pertinente, así como las modificaciones susceptibles de ser realizadas para su final publicación. Dicha notificación se enviará únicamente por correo electrónico, en un plazo máximo de seis meses. 


\section{Publishing rules}

The author is committed to submit original papers not having been published in other reviews or in other languages. In this way, it is not allowed for the same paper to be presented in other reviews during the evaluation process.

\section{Submission and presentation of originals}

The articles will be exclusively submitted by email to pantarei@um.es. The texts will be submitted in DOC format and the images in JPEG or TIFF format, and with a minimum size of 2000 px. Images will not be integrated in the text but sent in another file and properly numbered according to their position in the text. Attached to the paper, a document will be filled out and sent where the author's data will be specified following the model available on the website.

The sixth edition of the Manual of the American Psychological Association will be taken into account for the writing of the papers. The length of the papers must not exceed 30 pages. Typography will be Arial 11 , with simple line spacing and no space between paragraphs. The text must be justified on both margins without indentation in the first paragraphs. Margins size will be $2.50 \mathrm{~cm}$. Where it could be necessary the incorporation of notes, they will be at the bottom of the page, consecutively numbered with typography Arial 10, simple line spacing and justified on both margins.

More detailed information is available on the website: http://www.um.es/cepoat/pantarei.

\section{Examination and assessment process}

The Journal will submit the papers to a first examination once received. If the paper follows the presentation guidelines, the subject agrees with the editorial line of this journal, and possess the scientific quality required, it will be sent to the advisory council for a first assessment. If not, the documents which clearly fail to complete the editorial line may be rejected straightaway in this first step.

The Advisory Council will indicate the originality, relevance, structure, writing, bibliography, etc. of the text to the journal; for this purpose, two outside experts will be designated to review the papers; these experts can be (or not) part of this Advisory Council. The selection of the experts will adjust to the subject and methodological characteristics of the paper. Name and affiliation of the author will be eliminated from the text for its review, in this way experts will act anonymously and confidentially.

The experts will fill out an assessment report which will focus on aspects such as formal characteristics, originality and novelty of the papers, relevance and results of the proposal, methodological quality and scientific validity.

Once the process is finished, the acceptance or not of the papers and its publication in the corresponding edition will be decided, as well as the modifications that may be done for its final publication. This notification will be sent by email within 6 months maximum. 



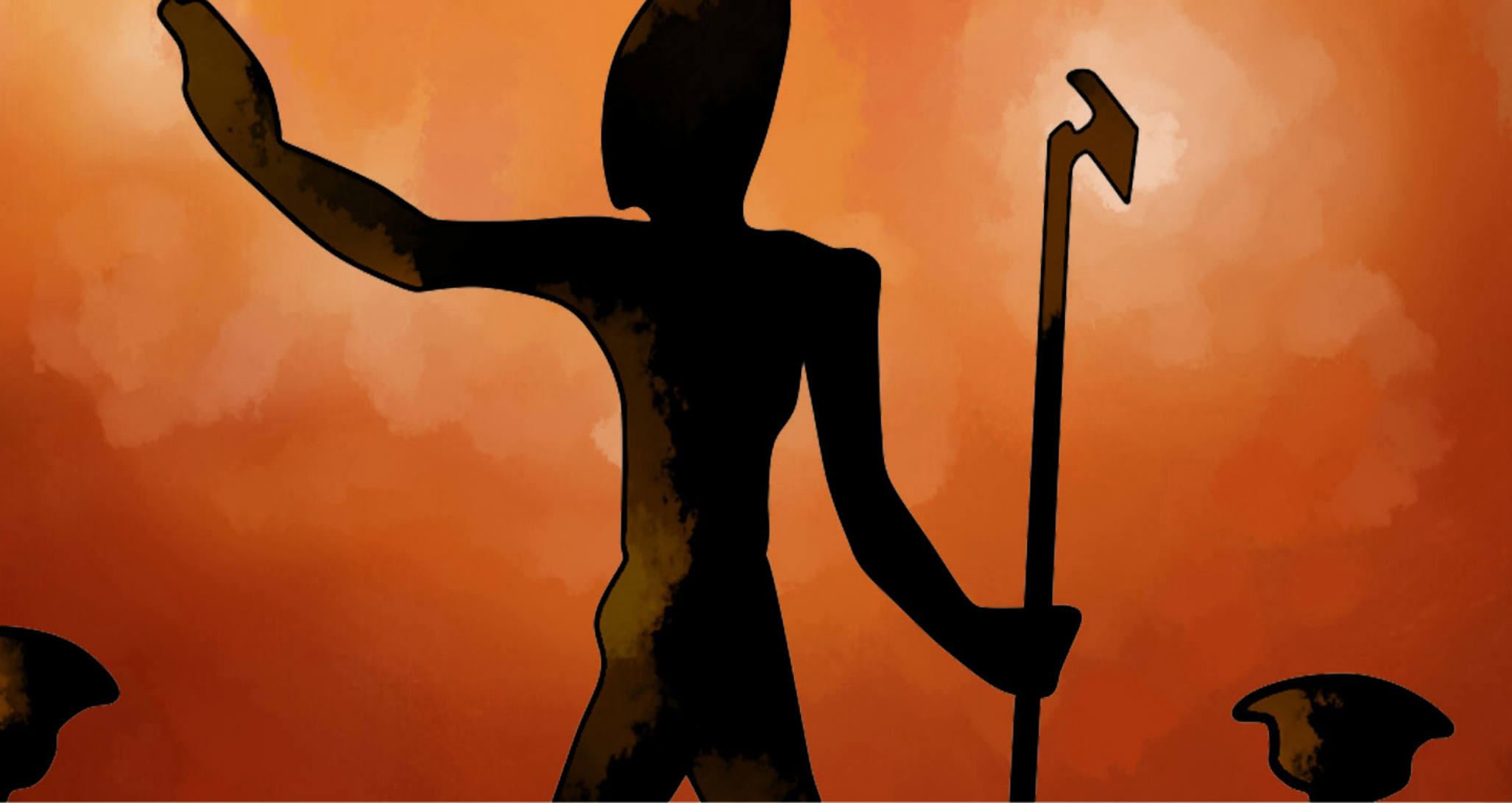

\section{cepoAt}

UNIVERSIDAD DE MURCIA

centro de estudios del

próximo oriente y la

antigüedad tardía 